\title{
Transient impedance of grounding system with impulse superimposed sinewave
}

\author{
Sherif S. M. Ghoneim, Ahdab M. Elmorshedy, and Rabah Y. Amer
}

\begin{abstract}
Investigating the transient performance of grounding systems subject to lightning (impulse or impulse superimposed sinewave) is valuable for protecting the power system and maintaining the system operation. In this work, the grounding system's impedance is computed when an impulse superimposed sinewave is applied to the grounding grid's proposed lumped circuit andthe grounding system can be simulated as an inductance in series with resistance, and all of them are in parallel with capacitance based on Thione's assumption. Several variables were investigated to study their effects on the grounding system's behavior. The variables were the soil resistivity, soil permittivity, main wire length, grid conductor radius, grid side length, grid configurationand its mesh number. The grounding system configuration varied between square and rectangular shapes, which connects to the protecting rod via the main wire conductor. A 3.69 $\mathrm{kA}$ peak of impulse current was applied to avoid soil ionization. The results indicated the performance of the grounding system when subjecting to impulse current.
\end{abstract}

Keywords - transient behavior, grounding systems, impedance, step response, lightning protection

\section{INTRODUCTION}

Grounding systems are utilized as a part of a lightning protection system providing an easy path to discharging current to pass into the ground. In this sense,the impedance of the designed grounding system must be as low as possible to avoid the excessive voltage rise, which harms the equipment and individuals [1-4].

The grounding systems' analysis subjected to lightning strokes is very complicated, especially with grounding grids where much research has been addressed to explain the performance of grounding impedance of the grounding grid under lightning $[5,6]$. The performance of grounding system when subjected to lightning is investigated through many techniques such as experimental works $[7,8]$, simplified computational methods [9], and numerical analysis $[10,11]$.

Some other approaches are analytical based on the circuit theory approach [12], which is based on replacing all conductor elements, including the lightning paths, with an equivalent electrical network. The circuit theory is a fast and straightforward calculation $[13,14]$. The network analysis leads directly to the results in terms of currents and voltages for all interest points. The other approach is the field theory approach [15], based on the direct solution of the electromagnetic field equations about the energized conductors and all metallic structures nearby, whether directly energized or not.

In this paper, the transient impedance of the grounding grid is computed when applying the impulse superimposed sinewave current. Furthermore, the influence of some grid and soil variables on the grounding system behavior was investigated.

Manuscript received February 10, 2021; revised April 16, 2021.

$S$. Ghoneim is with the Electrical Engineering Department, Taif University, Taif, SAUDI ARABIA (e-mail: s.ghoneim@tu.edu.sa).

A. Elmorshedy is with Electric Power and Machines Department, Cairo University, Giza,EGYPT (e-mail: ahdabmk@yahoo.com).

R. Amer is with Electric Power and Machines Department, Cairo

University, Giza,EGYPT (e-mail: rabah_amer@yahoo.com).
The variables were the soil resistivity, soil permittivity, main wire length, grid conductor radius, grid side length, grid configuration, and its mesh number.

\section{GROUNDING SYSTEM MODEL}

L. Thione observed that grounding conductors' response to an impulse current might be oscillatory [5]. As a result, the grounding systems' equivalent circuit should include an inductive part of the ground conductors' total inductance, directly in series to the ground resistance. Thus all of them are in parallel to ground capacitance, as in Fig. 1.

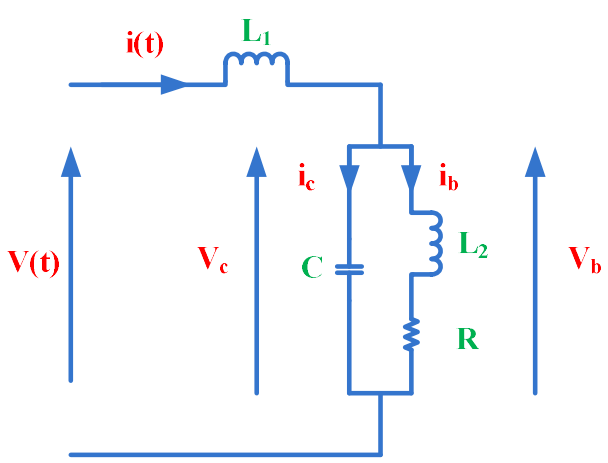

Fig. 1. Grounding system model.

Let the applied current, which is applied to the equivalent circuit in Fig. 1, is as follows,

$$
\begin{aligned}
& i(t)=A e^{-\lambda t} \sin \mu t, \\
& \text { where, } \\
& \begin{array}{l}
A=(\operatorname{Imax} \times 6.45 \mathrm{E} 8 / 3.69) \mathrm{kA}, \\
\lambda=1.21 \mathrm{E} 5(1 / \mathrm{s}) \\
\text { and } \mu=2.94 \mathrm{E} 5(\mathrm{rad} / \mathrm{s})
\end{array}
\end{aligned}
$$

As the derivation in [16], the applied voltage in s domain is as follows, 


$$
V(S)=\frac{A \mu}{(S+\lambda)^{2}+\mu^{2}} \times\left[S L_{1}+\frac{\left(S L_{2}+R\right)}{\left(L_{2} C S^{2}+R C S+1\right)}\right]
$$

where,

$$
R=\frac{\rho}{4 r}+\frac{\rho}{l} \Omega
$$

$\mathrm{R}$ refers to grounding resistance, $\rho$ is the soil's resistivity, $r$ is the equivalent radius of the grid, and 1 is the total grid length. The grid capacitance can be computed as follows,

$$
C=\frac{\varepsilon \rho \times 10^{-9}}{36 \pi R} \mathrm{f}
$$

Where $\varepsilon$ is the permittivity of the soil. The inductance of the grounding grid can be evaluated as follows,

$$
L_{2}=\frac{2 l^{\prime \prime}}{3 \times 10^{7}} \ln \frac{4 l^{\prime \prime}}{r^{\prime}} \mathrm{H}
$$

Where $\mathrm{l}^{\prime \prime}$ is the side length of the grid and $\mathrm{r}^{\prime}$ is the grid radius. where,

The inductance of the main wire can be determined as follows,

$$
L_{1}=\frac{2 l^{\prime \prime}}{3 \times 10^{7}} \ln \frac{2 l^{\prime \prime}}{r^{\prime \prime}} \mathrm{H}
$$

Where $1^{\prime \prime \prime}$ refers to the main wire length and $r^{\prime \prime}$ is the main wire radius.

Equation (1) can be rewritten as in (2),

$$
\begin{aligned}
& V(S)=\frac{A \mu S L_{1}}{(S+\lambda)^{2}+\mu^{2}} \\
& +\frac{A \mu\left(S L_{2}+R\right)}{\left((S+\lambda)^{2}+\mu^{2}\right)\left(L_{2} C S^{2}+R C S+1\right)}
\end{aligned}
$$

From (2), the first term can be rewritten as in (3),

$$
\frac{A \mu S L_{1}}{(S+\lambda)^{2}+\mu^{2}}=\left\{\begin{array}{l}
A \mu L_{1}\left\{\frac{(S+\lambda)}{(S+\lambda)^{2}+\mu^{2}}\right\} \\
-A \mu L_{1}\left\{\frac{\mu}{(S+\lambda)^{2}+\mu^{2}}\right\}
\end{array}\right\}
$$

Similarly, the second term in (2) can be rewritten as follows,

$$
\begin{aligned}
& \frac{A \mu(S L 2+R)}{\left((S+\lambda)^{2}+\mu^{2}\right)\left(L_{2} C S^{2}+R C S+1\right)} \\
& =\frac{U S+V}{\left((S+\lambda)^{2}+\mu^{2}\right)}+\frac{X S+Y}{\left(L_{2} C S^{2}+R C S+1\right)}
\end{aligned}
$$

where,

$$
\begin{aligned}
U= & \frac{-A \mu R C L_{2}-Y\left(1-C L_{2}\left(\lambda^{2}+\mu^{2}\right)\right)}{R C-2 \lambda C L_{2}}, \\
Y= & \frac{\left(R C-2 \lambda C L_{2}\right)\left(A L_{2} \mu-A \mu C R^{2}\right)}{W} \\
& -\frac{\left(-A \mu R C L_{2}\right)\left(1-C L_{2}\left(\lambda^{2}+\mu^{2}\right)\right)}{W} \\
W= & \left(R C-2 \lambda C L_{2}\right)\left(2 \lambda-C R\left(\lambda^{2}+\mu^{2}\right)\right) \\
& -\left(1-C L 2\left(\lambda^{2}+\mu^{2}\right)\right)^{2}
\end{aligned}
$$

$$
X=-C L_{2} U \text { and, } V=R A \mu-Y\left(\lambda^{2}+\mu^{2}\right)
$$

Then

$$
\begin{aligned}
& \frac{U S+V}{(S+\lambda)^{2}+\mu^{2}}=\frac{U S+V+U \lambda-U \lambda}{(S+\lambda)^{2}+\mu^{2}} \\
& =\frac{U S+\lambda}{(S+\lambda)^{2}+\mu^{2}}-\left(\frac{U \lambda}{\mu}\right)\left(\frac{\mu}{(S+\lambda)^{2}+\mu^{2}}\right) \\
& \quad+\left(\frac{V}{\mu}\right)\left(\frac{\mu}{(S+\lambda)^{2}+\mu^{2}}\right)
\end{aligned}
$$

And

$$
\begin{aligned}
& \frac{X S+Y}{S^{2} C L_{2}+S C R+1}=\frac{X S+Y}{C L_{2} \times X X} \\
& X X=S^{2}+2 \zeta \omega_{n} S+\omega_{n}{ }^{2}
\end{aligned}
$$

$$
\omega_{n}=\sqrt{\frac{1}{C L_{2}}} \text { and } \quad \zeta=\sqrt{\frac{C R^{2}}{4 L_{2}}}
$$

Then,

$$
\begin{aligned}
& \frac{X S+Y}{C L_{2}\left(S^{2}+2 \zeta \omega_{n} S+\omega_{n}^{2}\right)}=\frac{X}{C L_{2}}\left(\frac{S}{X X}\right) \\
& +\frac{Y}{C L_{2} \omega_{n}{ }^{2}}\left(\frac{\omega_{n}^{2}}{X X}\right)
\end{aligned}
$$

hence,

$$
\begin{aligned}
& V(S)=A \mu L_{1}\left(\frac{(S+\lambda)}{(S+\lambda)^{2}+\mu^{2}}\right) \\
& -A \mu L_{1}\left(\frac{\mu}{(S+\lambda)^{2}+\mu^{2}}\right)+\frac{U S+\lambda}{(S+\lambda)^{2}+\mu^{2}} \\
& -\frac{\mathrm{U} \lambda}{\mu}\left(\frac{\mu}{(S+\lambda)^{2}+\mu^{2}}\right)+\frac{V}{\mu}\left(\frac{\mu}{(S+\lambda)^{2}+\mu^{2}}\right) \\
& +\frac{1}{C L_{2}}\left(\frac{\mathrm{XS}}{\mathrm{S}^{2}+2 \zeta \omega_{\mathrm{n}} S+\omega_{\mathrm{n}}{ }^{2}}\right. \\
& \left.+\frac{Y}{\omega_{\mathrm{n}}{ }^{2}}\left(\frac{\omega_{\mathrm{n}}{ }^{2}}{\mathrm{~S}^{2}+2 \zeta \omega_{\mathrm{n}} S+\omega_{\mathrm{n}}{ }^{2}}\right)\right)
\end{aligned}
$$

Then, the voltage can be determined using inverse Laplace as follows,

$$
\begin{aligned}
& V(t)=\left(A \mu L+U_{1}\right) e^{-\lambda t} \cos \mu t \\
& +\left(\frac{V}{\mu}-\frac{U \lambda}{\mu}-A \mu L_{1}\right) e^{-\lambda t} \sin \mu t \\
& +\frac{1}{\beta}\left(\begin{array}{c}
\left(\frac{-X e^{-\zeta \omega_{n} t} \sin \left(\omega_{n} \sqrt{1-\zeta^{2}} t-\varphi\right)}{\sqrt{1-\zeta^{2}}}\right) \\
+\frac{Y}{\omega_{n}}\left(\frac{e^{-\zeta \omega_{n} t} \sin \left(\omega_{n} \sqrt{1-\zeta^{2}} t\right)}{\sqrt{1-\zeta^{2}}}\right)
\end{array}\right)
\end{aligned}
$$

As shown in [5], the effective inductance of long grounding is 
one-third of the grounding grid's total inductance, then $\mathrm{L}_{2}$ with the change in permittivity, which refers to the water should be modified to $\mathrm{L}_{2} / 3$ in (14). The impulse impedance is content.

then identified as in [16] as follows,

$$
Z_{\text {imp }}=\frac{\text { Crest value of } \operatorname{Voltage}\left(V_{m}\right)}{\text { Crest value of } \operatorname{Current}\left(I_{m}\right)}
$$

\section{TRANSIENT BEHAVIOR OF GROUNDING SyStem}

Figures 2 and 3 show the applied current waveforms and the output voltage on the square and rectangular grids with a similar area. The circuit's behavior seems to be an inductive circuit where the current seems to be lag for the developed voltage.

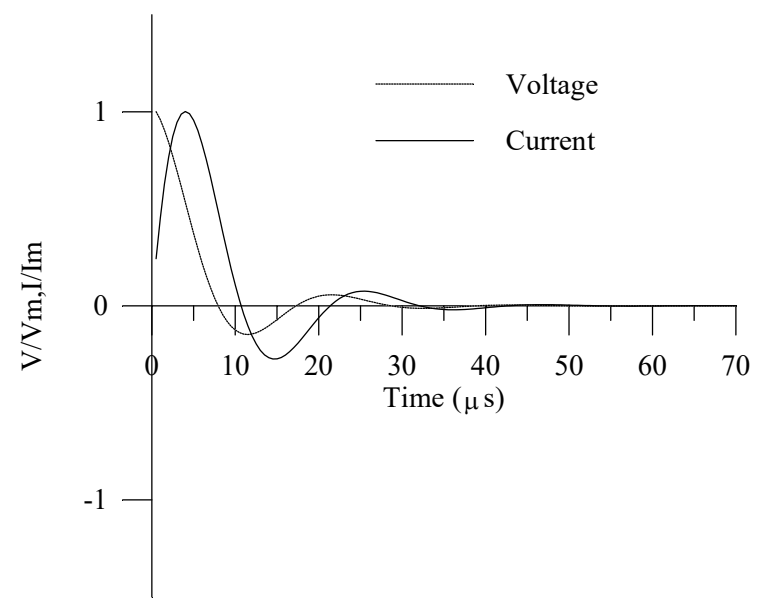

Fig. 2. Voltage and current waveshape for the square grid.

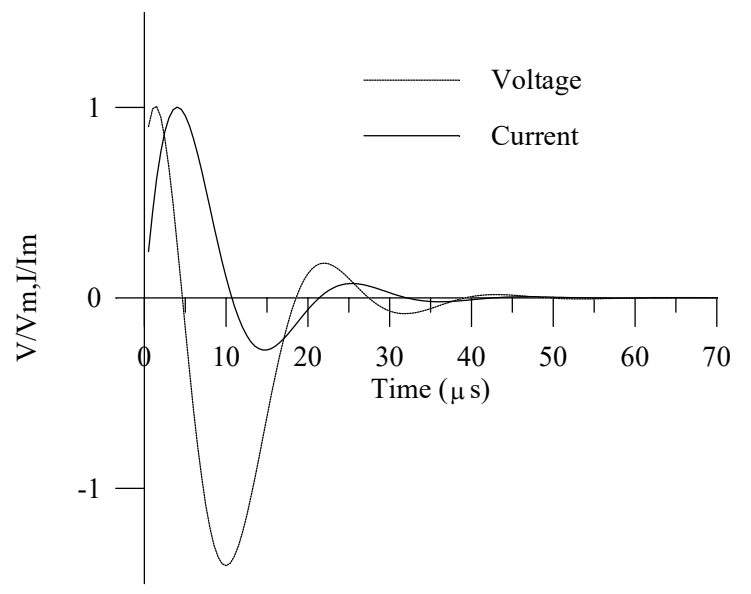

Fig. 3. Voltage and current waveshape for the rectangular grid.

IV. INVESTIGATING THE INFLUENCE OF SOME PARAMETERS ON THE TRANSIENT IMPEDANCE

\section{A. The Effect of Soil Characteristics}

The influence of soil resistivity, permittivity on the ground system's transient impulse impedance was illustrated. The effect is shown in the following Figures 4 and 5 .

The greater the resistivity, the greater the transient impulse impedance. The value of the impulse impedance as in (15) is high when the resistivity increases. The impulse impedance reaches to steady-state value after $10 \mu$ s in the case of a square grid but $8 \mu \mathrm{s}$ in the rectangular grid as in Fig. 4 .

Figure 5 shows no effect on the transient impulse impedance

\section{B. The Effect of Grid Parameters}

Figures from 6 to 10 explain the effect of the grid's side length, the radius of the conductor, the number of meshes, and the grid's width in the case of a rectangular grid.

The impulse impedance decreases as the grid side length increases. The impulse impedance with the variation of square grid length is lower than that in the side length variation of the rectangle grid.

The effect conductor radius on the impulse impedance is not significant, which is shown in Fig. 8. It is noted that the impulse impedance decreases moderately as an increase of the radius of the grid conductor (it reduces $25 \%$ when the conductor radius increases from $0.005 \mathrm{~m}$ to $0.25 \mathrm{~m}$ ) [17].

As in Fig. 9, the results explain that the number of meshes' changes causes a slight shift in transient impulse impedance. For the rectangular grid in Fig. 10, the grid's width variation causes a significant difference in the transient impulse impedance.

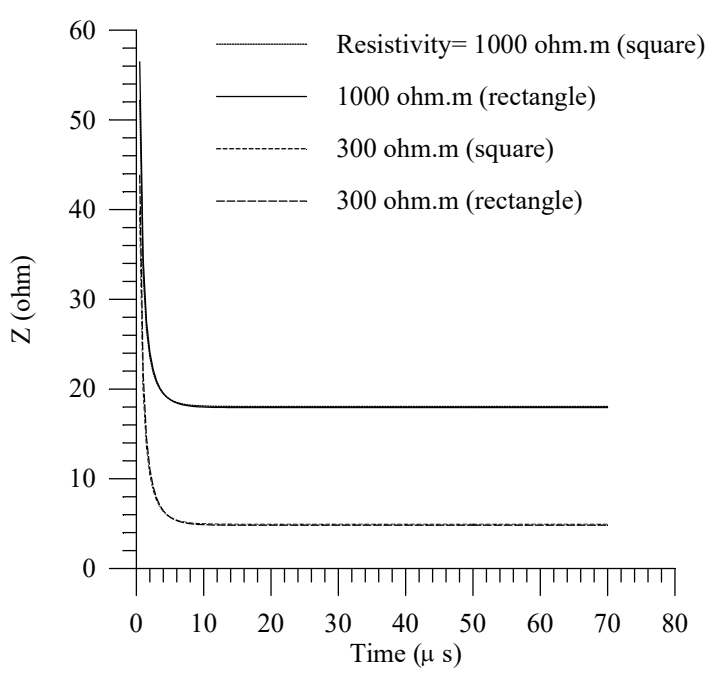

Fig. 4. Effect of the variation of resistivity on transient impulse impedance.

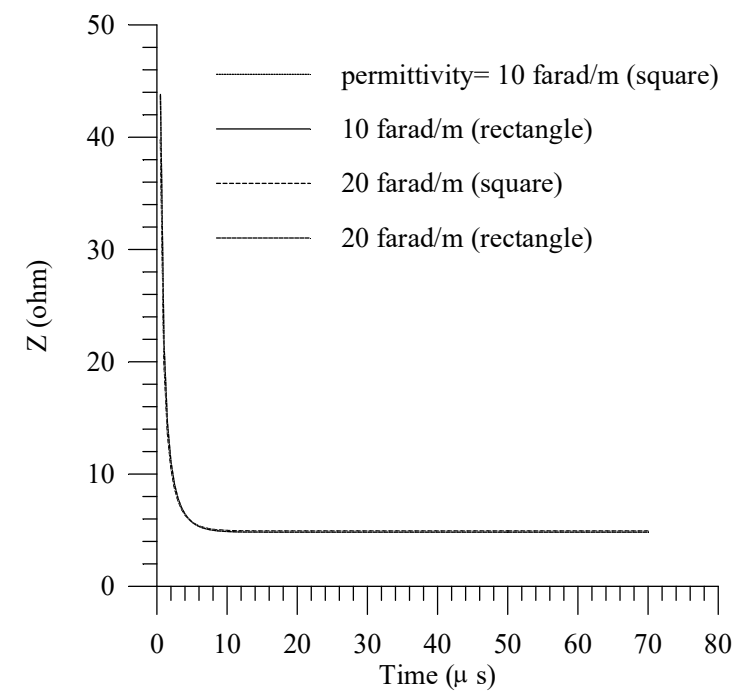

Fig. 5. Effect of the variation of permittivity on transient impulse impedance. 


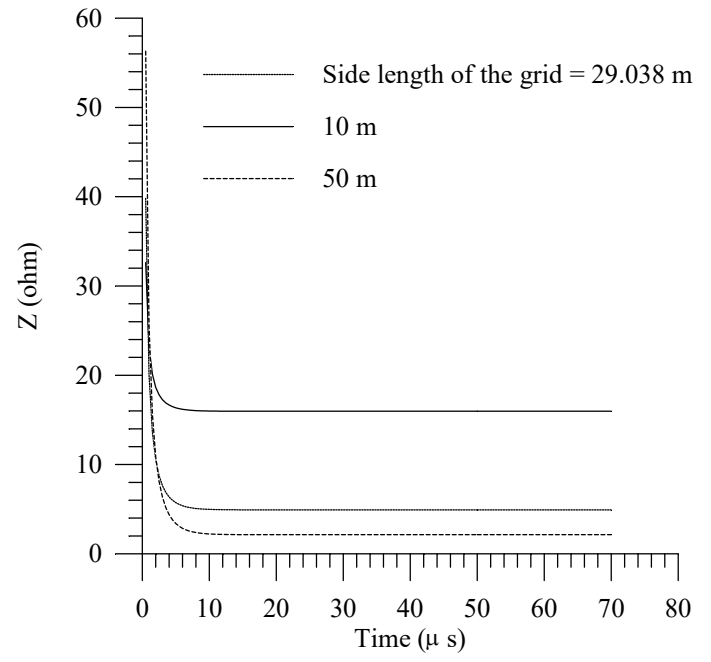

Fig. 6. Effect of the variation of side length on transient impulse impedance for square grid.

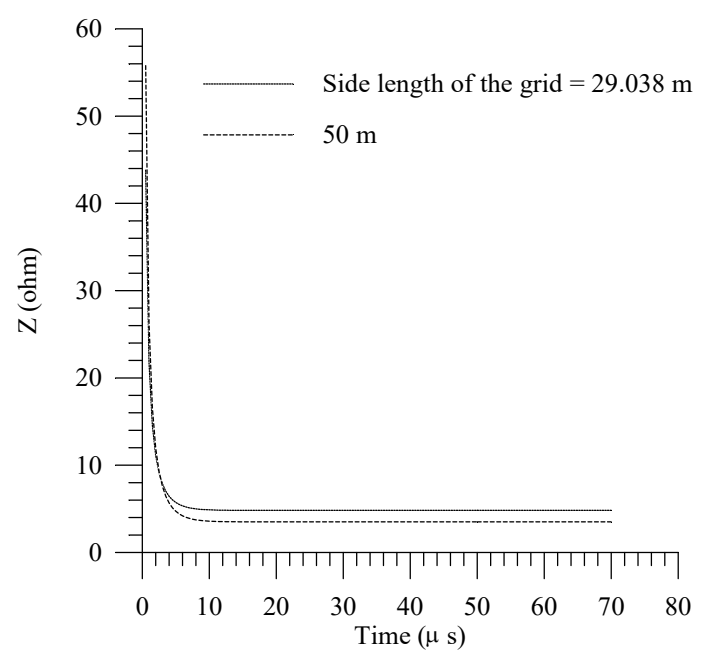

Fig. 7. Effect of the variation of side length on transient impulse impedance for the rectangular grid.

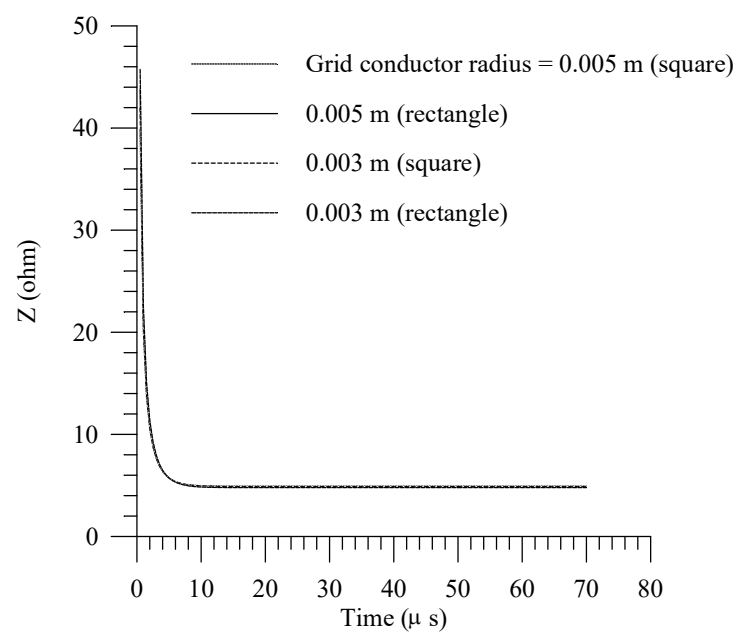

Fig. 8. Effect of the variation of grid conductor radius on transient impulse impedance.

\section{The Effect of Main Wire}

The effect of the main wire is studied. The main wire is the wire that transfers the surge current to the ground system, and it is inductive, which leads to the enhancement of the transient impulse impedance of the grid. The effect of the main wire is shown in Fig.11. An increase in the length of the main wire leads to a decrease in the impulse impedance.

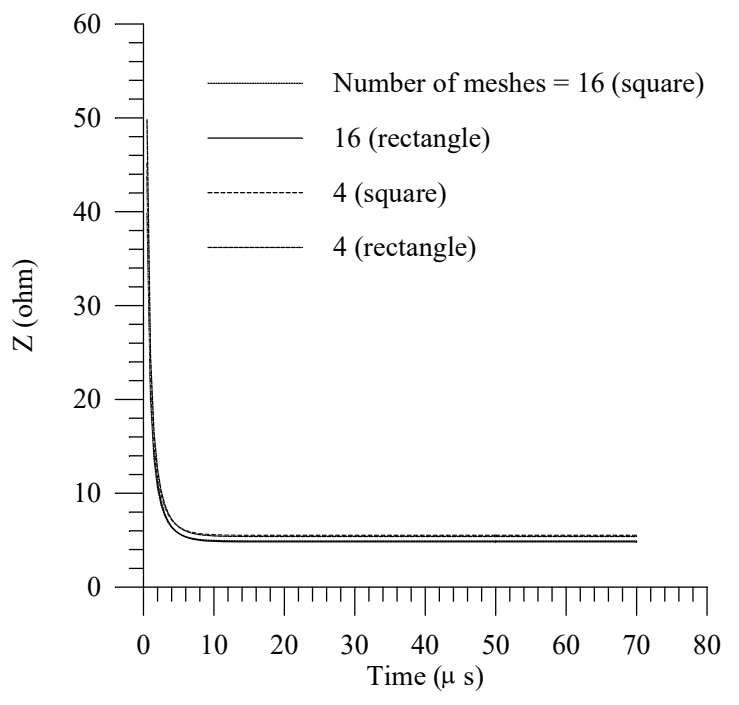

Fig. 9. Effect of the number of meshes on transient impulse impedance.

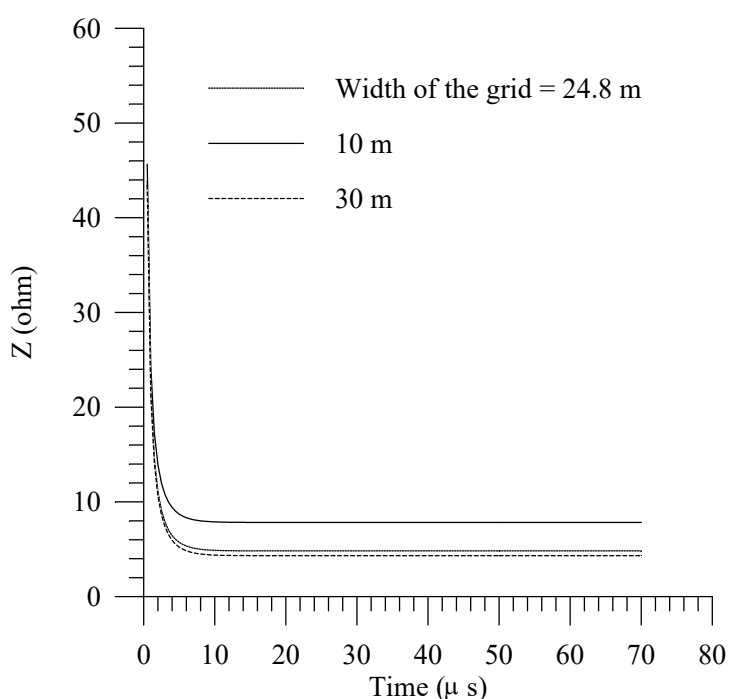

Fig. 10. Effect of the variation grid width on transient impulse impedance for the rectangular grid.

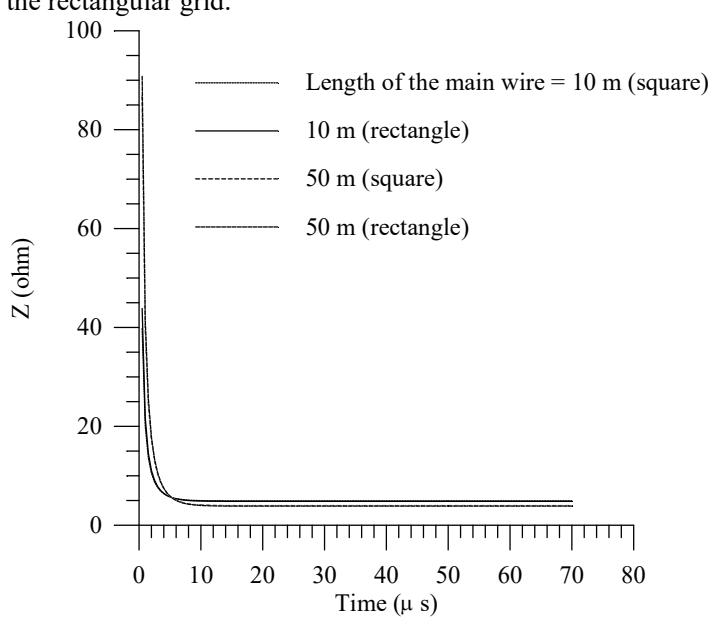

Fig. 11. Effect of the main wire length on transient impulse impedance.

\section{STEP RESPONSE}

The step response is used to express the grounding system's impulse impedance, which is convenient to understand the transient characteristics of the grounding system's impedance [9]. The following equation obtains the Step Response $\mathrm{Zu}(\mathrm{t})$ of a grounding impedance, 


$$
\begin{aligned}
& Z_{u}(s)=\frac{1}{s} \cdot \frac{L(V(t))}{L(i(t))} \\
& Z_{u}(t)=L-1\left(Z_{u}(s)\right)
\end{aligned}
$$

$\mathrm{V}(\mathrm{t})$ is the measured grounding voltage, $\mathrm{i}(\mathrm{t})$ is the measured injected current, $\mathrm{t}$ is the time, $\mathrm{s}$ is the Laplace operator, and $\mathrm{L}$ and L-1 are the Laplace forward inverse transforms.

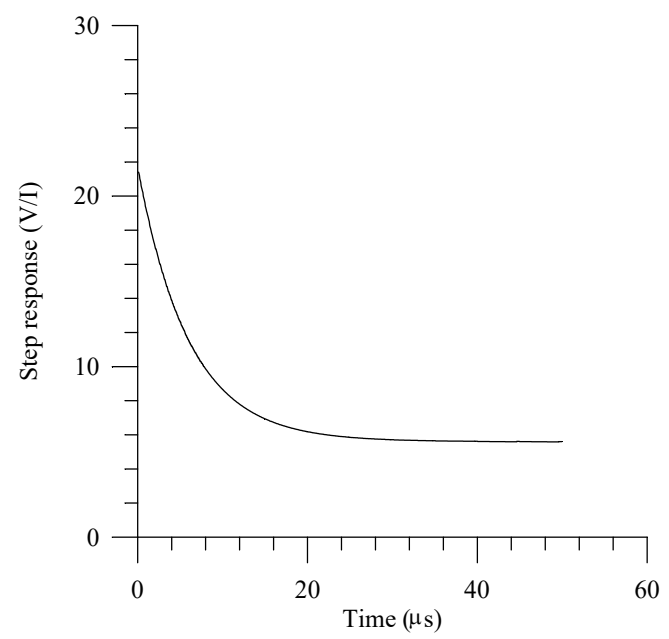

Fig. 12. Step response of grounding system.

\section{CONCLUSION}

The results obtained from the proposed circuit theory-based model help better understand the grounding systems' performance subjected to lightning (impulse superimposed sinewave). The step response is convenient to understand a transient characteristic of the impedance of the grounding system. When applying the proposed wave, the square grid configuration presents a low impedance for lightning in comparison to the rectangular one. The significant variation in transient impulse impedance occurs with the change of the soil's resistivity and the side length of the grid.

\section{REFERENCES}

[1] IEEE Standard Dictionary of Electrical and Electronics Terms, IEEE Std. 100-1992, Jan. 1993.

[2] Ed.1: Protection Against Lightning-Part 3: Physical Damage to Structures and Life Hazard, IEC 62305-3, 2006.

[3] IEEE Guide for Safety in AC Substation Grounding, IEEE Std.80-2000, May 2000.

[4] R. Xiong, B. Chen, C. Gao, Y. Yi, and W. Yang, "FDTD Calculation Model for the Transient Analyses of Grounding Systems", IEEE Trans. on Electromag. Compat., Vol. 56, No. 5, pp. 1155-1162, October 2014. https://doi.org/ 10.1109/TEMC.2014.2313918

[5] R. Verma and D. Mukhedkar, "Fundamental Considerations and Impulse Impedance of Ground Grids", IEEE Trans. on Power App. and Sys., Vol. Pas-100, pp. 2053-2059, March 1981. https://doi.org/ 10.1109/TPAS. 1981.316638

[6] G. Parise, L. Parise, L. Martirano, "Intrinsically Safe Grounding Systems and Global Grounding Systems" IEEE Trans. Ind. App., Vol. 54, issue 1, pp. 25 - 31, 2018. https://doi.org/10.1109/TIA.2017.2743074

[7] S. Visacro and R. Alipio, "Frequency dependence of soil parameters: Experimental results, predicting formula and influence on the lightning response of grounding electrodes," IEEE Trans. Power Del., vol. 27, no. 2, pp. 927-935, Apr. 2012 https://doi.org/10.1109/TPWRD.2011.2179070

[8] Z. Zhang, Y. Dan, J. Zou, G. Liu, C. Gao, Y. Li, "Research on Discharging Current Distribution of Grounding Electrodes", IEEE Access, Vol. 7, pp. 59287 - 59298, 2019. https://doi.org/10.1109/ACCESS.2019.2914058

[9] L. Grcev, "Modeling of grounding electrodes under lightning currents", IEEE Trans. on Electromag. Compat., Vol. 51, no. 3, pp. 559-571, Aug.2009. https://doi.org/10.1109/TEMC.2009.2025771

[10] N. Permal, M. Osman, M. Z. Ab. Kadir, A. M. Ariffin, "Review of Substation Grounding System Behavior Under High Frequency and Transient Faults in Uniform Soil ," IEEE Access, Vol. 8, pp. 142468 142482, 2020. https://doi.org/10.1109/ACCESS.2020.3013657
[11] R. Xiong, B. Chen, J. J. Han, Y. Y. Qiu,W. Yang, and Q. Ning, "Transient resistance analysis of large grounding systems using the FDTD method," Progress Electromagn. Res., vol. 132, pp. 159-175, 2012. https://doi.org/10.2528/PIER12082601

[12] O. Kherif, S. Chiheb, M. Teguar, A. Mekhaldi, N. Harid "TimeDomain Modelingof Grounding Systems' Impulse Response Incorporat ing Nonlinear and Frequency-Dependent Aspects", IEEE Transactions on Electromagnetic Compatibility, Vol. 60, No. 4, pp. 907 - 916, 2017. https://doi.org/10.1109/TEMC.2017.2751564

[13] L. Grcev, M. Popov, "On high-frequency circuit equivalents of a vertical ground rod", IEEE Trans. Power Deliv. 20(2), 1598-1603, 2005. https://doi.org/10.1109/TPWRD.2004.838460

[14] A. Taher, A. Said, T. Eliyan, A. Hafez, "Analysis and Mitigation of Ground Grid Lightning Potential Rise", Trans. on Elec. and Electronic Materials, pp. 1-11, 2020. https://doi.org/10.1007/s42341-020-00186-z

[15] W. Xiong, F. P. Dawalibi, "Transient Performance of Substation Grounding Systems Subjected to Lightning and Similar Surge Currents" IEEE Trans. on Power Del., Vol. 9, No. 3, pp. 1412-1420, July 1994. https://doi.org/ 10.1109/61.311170

[16] S. Sekioka, K. Tanemura, T. Sonpda, Y. Katyo, N. Nagaoka, and A. Ametani, "A Time- and Current-Dependent Grounding Impedance Model of a Grounding Net," International Conference on Electrical Engineering (ICEE'98) Vol. 1, pp. 832-835, 1998.

[17] F. P. Dawalibi, D. Mukhedkar "Parametric analysis of grounding grids" IEEE Trans. on Power App. and Sys., Vol. PAS-98, No. 5, pp. 16591667, Sep/Oct 1979. https://doi.org/ 10.1109/TPAS.1979.319484

[18] B. R. Gupta and V. K. Singh,"Impulse Impedance of Rectangular Grounding Grids, " IEEE Trans. on Power Del., Vol. 7, No. 1, pp. 214218, January 1992. https://doi.org/ 10.1109/61.108910

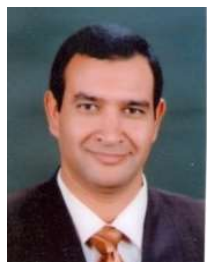

Sherif S. M. Ghoneim received his B.Sc. and M.Sc. degrees from the Faculty of Engineering at Shoubra, Zagazig University, Egypt, in 1994 and 2000. Since 1996, he has been teaching at the Faculty of Industrial Education, Suez Canal University, Egypt. From 2005 to 2007, he was a guest researcher at the Institute of Energy Transport and Storage (ETS) of the University of Duisburg-Essen in Germany. In 2008, he earned his Ph.D. degree in electrical power and machines from the Faculty of Engineering, Cairo University (2008). After that, he joined Taif University as an associate professor in the Electrical Engineering Department, Faculty of Engineering. His research areas include grounding systems, dissolved gas analysis, breakdown in SF6 gas, and AI technique applications.

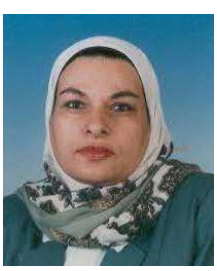

Ahdab Elmorshedy received the B.Sc., M.Sc., and Ph.D. in 1971, 1974, and 1978 respectively, in Electrical Engineering, from Cairo University, Egypt. Since 1971, she joined the faculty of Electrical Engineering at Cairo University, Egypt, as a Teaching staff. During the academic years of 1979 to 1981 , she was a research scientist in the Department of Electrical Engineering, College of Engineering at Ohio State University, Columbus, Ohio, U.S.A. Since 1988 she was a Professor at the Department of Electrical Engineering, Cairo University. Her research activities include grounding, protection and safety of power systems, over-voltage transients, and pollution of insulators. She is also an IEEE Member.

Rabah Amer received the B.Sc., M.Sc. and Ph.D. in 1975, 1979, and 1983 respectively, in Electrical Engineering, from Cairo University, Egypt. Since 1975, he joined the faculty of Electrical Engineering at Cairo University, Egypt as a Teaching staff. Since 1994 he was a Professor at the Department of Electrical Engineering, Cairo University. His research activities include grounding, gas discharge, electric and magnetic field calculations, predicting polluted insulators flashover using laser methods, lightning protection of petroleum companies, and overhead transmission line design and commissioning. Also, he is a consultant for petroleum, industrial and electrical companies. 